\section{Mosquitoborne Sindbis Virus Infection and Long-Term Illness}

\section{Åsa Gylfe, Assa Ribers, Oscar Forsman, Göran Bucht, Gerd-Marie Alenius, Solveig Wållberg-Jonsson, Clas AhIm, Magnus Evander}

Author affiliations: Umeå University, Umeå, Sweden

(Å. Gylfe, Å. Ribers, O. Forsman, G.-M. Alenius,

S. Wållberg-Jonsson, C. Ahlm, M. Evander); Swedish Defense

Research Agency, Umeå (G. Bucht)

DOI: https://doi.org/10.3201/eid2406.170892

An unexpected human outbreak of the mosquitoborne Sindbis virus occurred in a previously nonendemic area of Sweden. At follow-up, 6-8 months after infection, 39\% of patients had chronic arthralgia that affected their daily activities. Vectorborne infections may disseminate rapidly into new areas and cause acute and chronic disease.

$\mathrm{M}$ osquitoborne viruses such as chikungunya virus, Ross River virus, and Sindbis virus (SINV) are members of the genus Alphavirus (family Togaviridae) and cause human arthritic diseases (1). SINV has mainly been reported in northern Europe and South Africa (1); Sweden has an average of 3 SINV cases per year, with occasionally more cases in a previously defined endemic region in central Sweden (Figure) (2). Birds are the reservoir for SINV, and there is no evidence of human-tohuman transmission. SINV infection in humans, called Ockelbo disease in Sweden, causes rash, arthritis, and mild fever (3-5). Most patients recover within weeks or months, but arthralgia and myalgia can persist for years following infection, suggesting inflammatory response or a persistent infection (4-6).

In mid-August 2013, several patients with rash, arthralgia, and fever visited the healthcare center in the small village of Lövånger in Västerbotten County, Sweden (Figure). The university hospital laboratory in Umeå received 172 blood samples from patients with suspected SINV infection; 50 patients had SINV-specific IgM and IgG (online Technical Appendix, https://wwwnc.cdc.gov/ EID/article/24/6/17-0892-Techapp1.pdf). SINV infections have been believed to be almost exclusively confined to the central part of Sweden (2), but the 2013 outbreak occurred north of the endemic area (Figure). The distribution of verified cases by sex in this outbreak showed a higher proportion of female patients $(62 \%)$ than male patients $(38 \%)$ with acute SINV infection (online Technical Appendix Table 1).
Previous reports suggested that joint symptoms might persist for years in SINV infections (4-6). To evaluate long-term consequences, we contacted 46 SINV patients by telephone $3-4$ months, $6-8$ months, or in both periods after acute disease (online Technical Appendix Figure 1). Our study was approved by the Regional Ethics Review Board (2014-102-32M), and we obtained written informed consent from all participants. We include details of the study results summarized here in the online Technical Appendix. In total, 18/46 (39\%) of the patients reported persistent musculoskeletal pain (arthralgia and myalgia) and restriction in their daily activity 6-8 months after the onset of acute symptoms (online Technical Appendix Table 2). We invited these patients for a standardized examination by a rheumatologist, including a health assessment

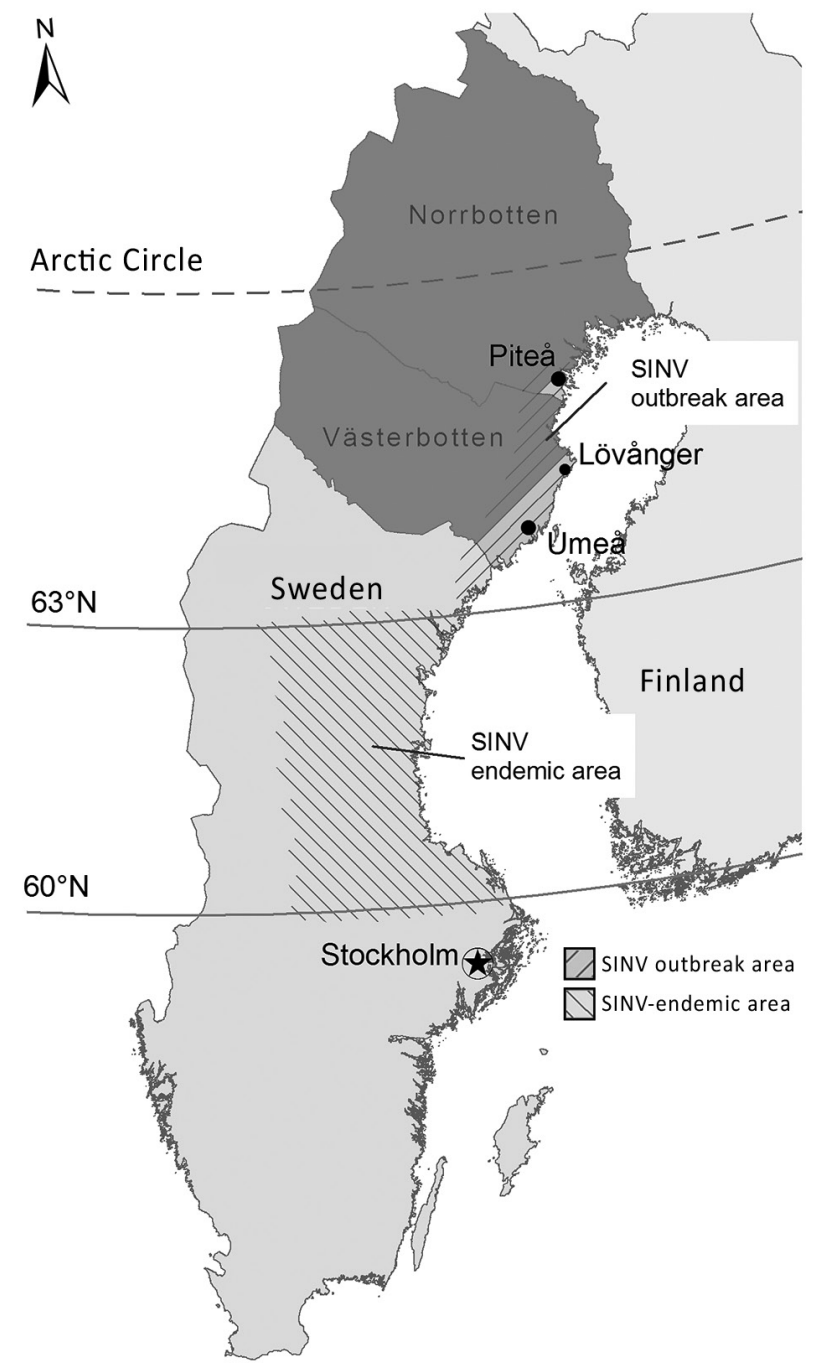

Figure. Geographic distribution of the SINV outbreak in 2013 and previous occurrence of SINV infections in Sweden. Dark gray indicates the 2 northernmost counties in Sweden where the SINV IgG seroprevalence was $2.9 \%$ in 2009 . SINV, Sindbis virus. 
questionnaire, patient assessments of their pain and their global health using a visual analog scale, and a blood sample (online Technical Appendix). Of 17 symptomatic patients who participated, 1 had arthritis in the ankle, 14 had $>1$ tender joint, and 10 had enthesitis, tendinitis, or tenosynovitis at examination. Large joints (knee, hip, shoulder, wrists, ankles) and small joints (toes, fingers) were affected, with a predominance for the lower extremities, in contrast to other studies in which small and peripheral joints were mainly affected (4-6). Patients graded their global symptoms as more severe than the examining doctor did, indicating that joint function was only mildly affected whereas the pain was perceived as restricting. Test results did not detect citrulline antibodies, and the single patient with positive rheuma factor had no arthritic symptoms. A notable finding was that 4 patients $(24 \%)$ had psoriasis, a condition present in $<4 \%$ of the northern European population (7), raising the question whether psoriasis makes SINV patients more vulnerable to long-term arthralgia.

We asked the 28 patients at the 6- to 8-month follow-up who had recovered to complete a questionnaire and donate a blood sample at their local healthcare provider; 23 did so. Symptomatic patients reported more pain and impaired health, compared with patients who were asymptomatic 6-8 months after acute disease. We detected SINV-specific IgM in patients with and without persistent symptoms, as previously reported (5).

We isolated a new SINV strain from a mosquito caught in the area during the outbreak; it was most closely related to a SINV strain from Finland (8). However, no increased incidence was recorded in Finland either the year before or concomitantly with the Swedish outbreak (9). In addition, only 1 case was reported from the endemic area of central Sweden in 2013, suggesting that local factors such as weather conditions may determine an outbreak. June 2013 stood out with a high mean temperature and precipitation, which have been shown to be associated with a high incidence of SINV infection later in summer (online Technical Appendix Figure 2).

A recent study in northern Sweden revealed that in a randomly selected population-based cohort, $2.9 \%$ had SINV IgG (Figure), indicating that the virus was present in the region, although not recognized (10). More research is warranted regarding the long-lasting joint pain caused by a previous SINV infection; patients with undiagnosed SINV may visit a healthcare facility with such symptoms even several months postinfection. Our report illustrates how a vectorborne zoonotic disease can result in a large, unexpected outbreak. The key factors for outbreaks of SINV or other alphavirus-caused diseases are generally unknown, which warrants further investigations, especially in light of the global emergence of alphaviruses (1).

\section{Acknowledgments}

We thank Maj Bylund for technical assistance.

The study was supported by the County Council of Västerbotten, the Swedish Research Council Formas (grant no. 221-2014-1556), the Medical Faculty of Umeå University, and the Arctic Research Center at Umeå University, ARCUM.

\section{About the Author}

Dr. Gylfe is a resident in clinical microbiology working at Umeå University and Norrlands University Hospital. Her major research interest is novel antimicrobial compounds.

\section{References}

1. Lwande OW, Obanda V, Bucht G, Mosomtai G, Otieno V, Ahlm C, et al. Global emergence of Alphaviruses that cause arthritis in humans. Infect Ecol Epidemiol. 2015;5:29853. http://dx.doi.org/10.3402/iee.v5.29853

2. Lundström JO, Vene S, Espmark A, Engvall M, Niklasson B. Geographical and temporal distribution of Ockelbo disease in Sweden. Epidemiol Infect. 1991;106:567-74. http://dx.doi.org/ $10.1017 / \mathrm{S} 0950268800067637$

3. Adouchief S, Smura T, Sane J, Vapalahti O, Kurkela S. Sindbis virus as a human pathogen-epidemiology, clinical picture and pathogenesis. Rev Med Virol. 2016;26:221-41. http://dx.doi.org/10.1002/rmv.1876

4. Niklasson B, Espmark A. Ockelbo disease: arthralgia 3-4 years after infection with a Sindbis virus-related agent. Lancet. 1986;327:1039-40. http://dx.doi.org/10.1016/ S0140-6736(86)91315-2

5. Niklasson B, Espmark A, Lundström J. Occurrence of arthralgia and specific IgM antibodies three to four years after Ockelbo disease. J Infect Dis. 1988;157:832-5. http://dx.doi.org/10.1093/ infdis/157.4.832

6. Kurkela S, Helve T, Vaheri A, Vapalahti O. Arthritis and arthralgia three years after Sindbis virus infection: clinical follow-up of a cohort of 49 patients. Scand J Infect Dis. 2008;40:167-73. http://dx.doi.org/10.1080/00365540701586996

7. Christophers E. Psoriasis-epidemiology and clinical spectrum. Clin Exp Dermatol. 2001;26:314-20. http://dx.doi.org/10.1046/ j.1365-2230.2001.00832.x

8. Bergqvist J, Forsman O, Larsson P, Näslund J, Lilja T, Engdahl C, et al. Detection and isolation of Sindbis virus from mosquitoes captured during an outbreak in Sweden, 2013. Vector Borne Zoonotic Dis. 2015;15:133-40. http://dx.doi.org/ 10.1089/vbz.2014.1717

9. National Institute for Health and Welfare, Finland. Registry of communicable diseases, statistical database [in Swedish] [cited 2018 Apr 6]. https://sampo.thl.fi/pivot/prod/sv/ttr/ shp/fact_shp?row=area-12260\& column=time-12059\& filter=reportgroup-12074

10. Ahlm C, Eliasson M, Vapalahti O, Evander M. Seroprevalence of Sindbis virus and associated risk factors in northern Sweden. Epidemiol Infect. 2014;142:1559-65. https://doi.org/10.1017/ S0950268813002239

Address for correspondence: Magnus Evander, Umeå University, Department of Clinical Microbiology, Virology, 901 85, Umeå, Sweden; email: magnus.evander@umu.se 